\title{
Twisted ovarian cyst in pregnancy: a case report
}

\author{
Amina Kuraishy*, Nasreen Noor, Zehra Mohsin \\ Department of Obstetrics and Gynecology, Jawahar Lal Nehru Medical College, AMU, Aligarh, Uttar Pradesh, India
}

Received: 24 May 2018

Accepted: 26 June 2018

\section{*Correspondence:}

Dr. Amina Kuraishy,

E-mail: aminakur234@gmail.com

Copyright: $\odot$ the author(s), publisher and licensee Medip Academy. This is an open-access article distributed under the terms of the Creative Commons Attribution Non-Commercial License, which permits unrestricted non-commercial use, distribution, and reproduction in any medium, provided the original work is properly cited.

\begin{abstract}
Ovarian cysts are frequently encountered during pregnancy due to the use of routine prenatal ultrasound. Most of them are benign but in some cases, complications can occur such as torsion, rupture and malignant change. In pregnancy risk of torsion increases 5-fold. It carries significant risk to a pregnant woman and her intrauterine foetus. Here we are reporting a 30-year-old female G3 P1+1L2 with 15 weeks of gestation who presented to antenatal OPD with complain of dull aching abdominal pain for 1 month and nausea and vomiting for 5 days. On ultrasound bilateral ovarian cysts were found, with one of the cyst with multiple septations. She underwent laparotomy, a right sided twisted ovarian cyst was found for which salpingoophrectomy was done. Left sided cyst was simple where cystectomy was done. Her histopathology report showed a bilateral benign serous cystadenoma. Her pregnancy was followed up. She delivered a healthy male baby at term. Ovarian cyst diagnosed in pregnancy can be followed up with serial ultrasound but if associated with complication such as torsion then urgent surgical intervention has to be done.
\end{abstract}

Keywords: Ovarian cyst torsion, Serous cystadenoma

\section{INTRODUCTION}

With the dawn of routine antenatal ultrasound, incidence of ovarian cyst in pregnancy is increasing. It is seen in 2$5 \%$ of pregnancies. ${ }^{1}$ Most of the ovarian cyst are benign but can be malignant also, which is a rare condition. Usually they are asymptomatic and are discovered on routine antenatal ultrasound. But sometimes patient can have acute pain abdomen, distension, nausea and vomiting which occurs due to torsion or rupture of the ovarian cyst.

Torsion of ovary or ovarian cyst is the total or partial rotation around its vascular axis or pedicle. A cyst which is freely mobile and have long pedicle undergoes torsion frequently. Pregnancy is also a predisposing factor for torsion. Incidence of adnexal torsion is 5 per 10,000 pregnancies. $^{2}$ For the diagnosis of ovarian cyst in pregnancy the ultrasound is reasonably accurate modality for detection and assessment adnexal mass and also for detection of risk for malignancy. Ultrasound should be considered as first imaging modality of investigation for ovarian mass in pregnant or non-pregnant women. It is safe in pregnancy. Colour Doppler studies can detect torsion of cyst. ${ }^{3}$ MRI can be safely used in pregnancy especially in third trimester when the evaluation with ultrasound is difficult. ${ }^{4}$ Benign ovarian cysts can be managed conservatively. But if complicated by torsion or rupture, then emergent surgical intervention is required irrespective of gestational age.

Here, we are reporting a case of torsion of ovarian cyst during second trimester of pregnancy with no known predisposing factors.

\section{CASE REPORT}

A 30-year-old female G3 P1+1L2 with 15 weeks of gestation presented to antenatal OPD with complain of dull aching abdominal pain for 1 month and nausea and 
vomiting for 5 days. Pain was present in whole abdomen which was dull aching in nature. There were no aggravating factors, but pain used to subside on taking some medications. Bowel and bladder was normal and regular. Since 5 days pain had increased and it was associated with nausea and vomiting. For these complaints she presented to us in OPD. There was no history of syncopal attack, fever, burning micturition, bleeding or discharge per vaginum. Her previous menstrual cycles were regular.

She conceived spontaneously. She had twin daughters of 5-year age born through caesarean section and one spontaneous abortion 2 years back. There was no significant past, personal or family history. Vital were stable, pulse rate - 90/min, BP - 116/74 mmHg, respiratory rate $16 / \mathrm{min}$ and temperature $98.4 \mathrm{~F}$. Systemic examinations were within normal limits. Abdominal examination revealed fundal height of 28 weeks, consistency in the upper part was cystic and tender on deep palpation.

Ultrasonography was done which showed a single live intrauterine pregnancy of 14-week 6 days gestation with bilateral adnexal masses measuring $141 \mathrm{~mm} \times 111 \mathrm{~mm}$ in the right adnexa and $60 \mathrm{~mm} \times 74 \mathrm{~mm}$ in the left adnexa. Right adnexal cyst had multiple septations and left adnexal cyst was simple unilocular. Her CA 125 levels were $65.3 \mathrm{U} / \mathrm{ml}$. Patient was taken up for laparotomy. During laparotomy $(15 \times 15) \mathrm{cm}$ blackened cystic mass was found in the right adnexa which was twisted two times around its pedicle as shown in Figure 1.

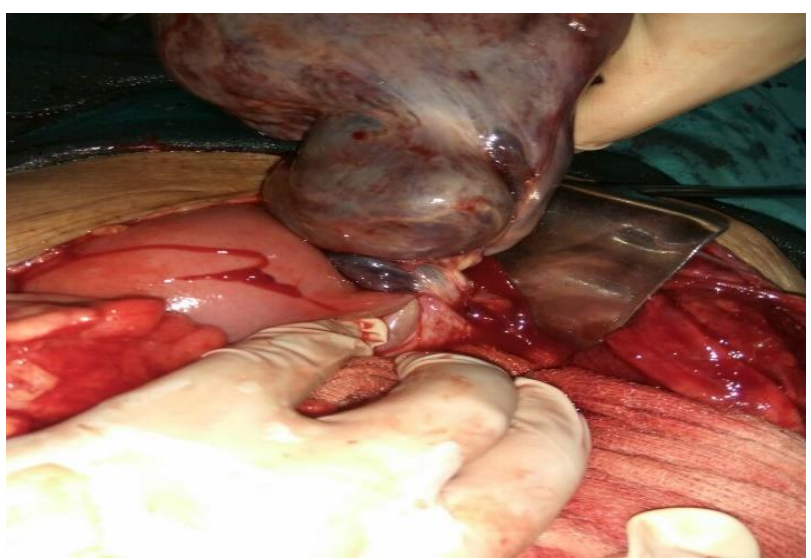

Figure 1: Twisted ovarian cyst.

Right fallopian tube was found to be gangrenous and was attached to the cyst. Omentum was loosely adhered to it as shown in Figure 2. Flimsy adhesions were removed, torsion was released and right sided salpingooophrectomy was done as the healthy ovarian tissue was not seen. Uterus was found to be 14-16 weeks in size. On the left side unilocular cyst of around $6 \mathrm{~cm}$ was seen and cystectomy was done. Her postoperative period was uneventful and was discharged on $8^{\text {th }}$ postoperative day after stitch removal.

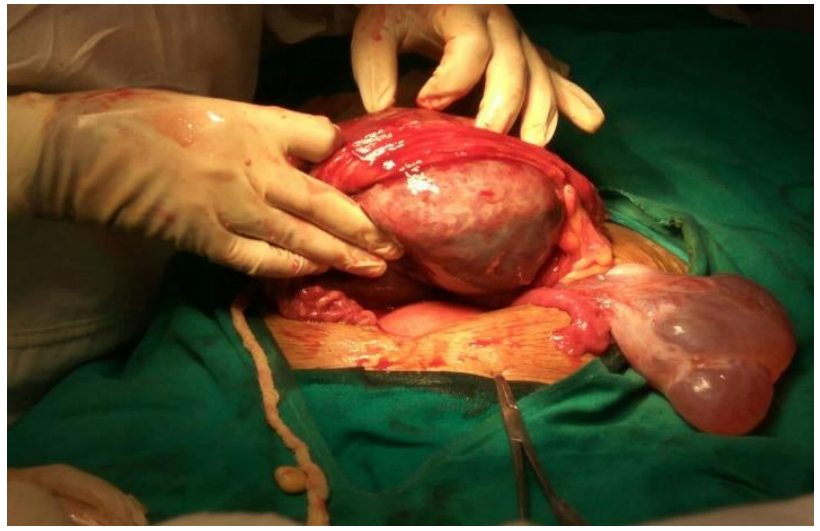

Figure 2: Ovarian cyst with omental adhesions.

Final diagnosis was made after histopathology report, which revealed bilateral benign serous cystadenoma. Her antenatal period was uneventful, and she delivered a healthy male baby through caesarean section done for non-progress of labour.

\section{DISCUSSION}

Most of the ovarian cyst which is found in pregnancy is functional cyst of the ovary such as follicular cyst, corpus luteal cyst and haemorrhagic cyst. The other benign ovarian masses found are cystic teratomas, serous cyst adenomas, mucinous cystadenomas, paraovarian cysts and endometriomas. ${ }^{5}$ Rarely malignant masses are found. The serous cystadenomas are thin walled, translucent cysts usually unilocular, may have few septations. size can vary between $20-30 \mathrm{cms}$. They are often unilateral but can be bilateral also.

As in our case it was bilateral. They are mostly benign but $10-15 \%$ of them are borderline malignant and $20-40 \%$ are malignant. ${ }^{6}$ They are often incidentally diagnosed in prenatal ultrasound as they are mostly asymptomatic. Complications can occur such as torsion, rupture, infection, malignancy, impaction of cyst in pelvis causing retention of urine, obstructed labour and malpresentations of the foetus. Torsion is the most common complication among them. The risk of ovarian torsion rises by 5 -fold during pregnancy. ${ }^{2}$ It is more common during first trimester, than in second trimester and rarely in third trimester. ${ }^{7}$ Our patient presented with ovarian torsion in second trimester.

If the torsion has occurred, patient can present with acute pain abdomen which is severe, colicky and non-remitting but can wax and wane in cases of incomplete or intermittent ovarian torsion. In above mentioned case, the patient had history of dull aching pain for one month which may be due to incomplete torsion. Diagnosis can be readily made with ultrasound of pelvis, which detects ovarian cyst. Benign or malignant nature of the cyst can also be made with it and doppler can detect torsion. On ultrasound serous cystadenoma is found to be unilocular (occasionally bilocular), with a thin, smooth wall, a thin, 
regular septum and homogeneous anechoic content. ${ }^{8}$ If the cysts contain septae, nodules, papillary excrescences or solid components then, malignancy is suspected. ${ }^{9}$ Management depends on size of the cyst, ultrasound features and signs and symptoms of the patient. Those with simple cystic appearance and size less than $6 \mathrm{~cm}$ can be managed expectantly with serial ultrasound surveillance, as most of them resolve spontaneously. ${ }^{10}$ Large cysts of more than $10 \mathrm{~cm}$ are usually resected due to fear of complications like torsion, rupture and increase chances of malignancy. About $50 \%$ of them may require emergency exploratory laparotomy for rupture, torsion or infarction. $^{9}$

The management is debatable in case of size $6-10 \mathrm{~cm}$. If there are solid components, papillary excrescences, septae and nodules then its better to remove them because of increase in risk of malignancy. Tumour markers such as CA 125 show little clinical significance in pregnancy as it is elevated in the first trimester of pregnancy and declines with advancing gestational age. ${ }^{11}$ Similarly, in our case elevated CA 125 was found to be raised but the cyst was found to be benign. Ovarian cysts diagnosed during first trimester of pregnancy can be managed conservatively only if there are no features of malignancy and no complications. The optimal time for surgical intervention during pregnancy is between 16 and 28 weeks of gestation. However immediate surgical intervention may be need irrespective of gestational age, in cases of ovarian torsion, rupture and malignancy. ${ }^{9,12,13}$

\section{CONCLUSION}

Ovarian cyst gets frequently diagnosed during pregnancy during a routine antenatal ultrasound. The majority of these are benign cysts which resolve spontaneously. Sometimes these cysts can create complications such as torsion, rupture, infarction, obstruction and very rarely can become malignant. Such conditions should be managed on an emergency basis in the view of maternal and fetal benefit.

\section{Funding: No funding sources Conflict of interest: None declared Ethical approval: Not required}

\section{REFERENCES}

1. Bignardi T, Condous G. The management of ovarian pathology in pregnancy. Best Pract Res Clin Obstet Gynaecol. 2009;23:539-48.
2. Ventolini G, Hunter L, Drollinger D, Hurd WW. Ovarian torsion during pregnancy. MD Magazine. 2007. Available https://www.mdmag.com/journals/resident-andstaff/2005/2005-09/2005-09_04

3. Valentin L. Use of morphology to characterize and manage common adnexal masses. Best Pract Res Clin Obstet Gynaecol. 2004;18(1):71-89.

4. Sherer DM, Maitland CY, Levine NF, Eisenberg C, AbulaWa O. Prenatal magnetic resonance imaging assisting in differentiating between large degenerating intramural leiomyoma and complex adnexal mass during pregnancy. J Matern Fetal Med. 2000;9(3):186-9.

5. Leiserowitz GS, Xing G, Cress R, Brahmbhatt B, Kalrymple JL, Smith LH. Adnexal masses in pregnancy: how often are they malignant? Gynecol Oncol. 2006;101(2):315-21.

6. Lee CH, Raman S, Sivanesaratnam V. Torsion of ovarian tumors: a clinicopathological study. Int J Gynaecol Obstet. 1989:28:21-5.

7. Hibbard LT. Adnexal torsion. Am J Obstet Gynecol. 1985;152:456-61.

8. Buy JN, Ghossain MA, Sciot C, Bazot M, Guinet C, Pr'evot S, et al. Epithelial tumors of the ovary: CT findings and correlation with US. Radiol. 1991;178:811-8.

9. Yen CF, Lin SL, Murk W, Wang CJ, Lee CL. Risk analysis of torsion and malignancy for adnexal mases during pregnancy. Fertil Steril. 2009;91:1895-902.

10. Duic Z, Kukura V, Ciglar S, Podobnik M, Podgajski M. Adnexal masses in pregnancy: a review of eight cases undergoing surgical management. Eur $\mathbf{J}$ Gynaecol Oncol. 2002;23:133-4.

11. Condous G, Kirk E, Syed A, Van Calster B, Van Huffel S, Timmerman D, et al. Do levels of serum cancer antigen 125 and creatine kinase predict the outcome in pregnancies of unknown location? Hum Reprod. 2005;20(12):3348-54.

12. Swensen RE, Goff BA, Koh WJ. Cancer in the pregnant patient. In: Hoskins WJ, Perez CA, Young RC (editor). Principles of Gynecologic Oncology. Lippincott Williams \& Wilkins, Philadelphia; 2005:1279-1311.

13. Ramadoss R, Abhinaya P, Hameed J, Narmadha N, Radhika S. Dilemma in the management of ovarian cyst in pregnancy: a series of three different cases. IJSS Case Rep Rev. 2015;1(8):10-3.

Cite this article as: Kuraishy A, Noor N, Mohsin Z. Twisted ovarian cyst in pregnancy: a case report. Int J Reprod Contracept Obstet Gynecol 2018;7:338991. 